\title{
OPPORTUNITY COST ANALISYS OF THE SALE OF PARAGUAYAN ENERGY FROM ITAIPU TO THE BRAZILIAN MARKET BASED ON A AHP MODEL
}

\begin{abstract}
Abundance of clean and renewable electricity has the potential to be a strategic asset for economic and social development. Besides being a booster of productivity and wellbeing, when abundant such as in the case of Paraguay, it can contribute to generating economic rents through its commercialization and/or promote industrial development processes that could leverage the country's development. The strategic use of the surplus hydroelectricity can arguably be a key to drive a socioeconomic transformation process.
\end{abstract}

Past works have considered several policy options to answer Paraguay's "surplus question". One is selling it to neighboring countries, another one encouraging the consumption of hydroelectricity energy through the installation of industries, thus generating jobs and mobilizing the domestic economy. It has been concluded that boosting industrial development could have a noticeable impact on the development of the country. At least partially, both strategies -export and use- are mutually exclusive, because the exported energy resigns a potential alternative strategy. Following this, choosing any of the alternatives instead of the other will be linked to an opportunity cost, defined as the maximum value among the options not made. Particularly for countries like Paraguay, that are on their way to achieve higher levels of economic and human development the costs of not taking full advantage of its strategic advantages is paramount.

This paper proposes a methodology to determine the opportunity costs of selling Paraguay's energy surplus in the Brazilian electricity market, as opposed to following other strategies. To evaluate the opportunity cost, several criteria are important. This is crucial as in this decision stakes are exceptionally high, and all criteria-economic, social, technical and political- must be considered.

Keywords: AHP, Electric Energy, Energy Policy, Opportunity Cost

\section{Introduction}

The abundance of electricity, clean and renewable, is a strategic asset for the development of countries. This resource has the potential to contribute to the economic growth and social progress of a country, generating economic rents through its commercialization and/or promoting industrial development processes that could significantly leverage the country's development and improve the quality of life of the population.

Given this context, it is necessary to highlight the particular case of Paraguay due to its great availability of hydroelectric power based on its participation in the Itaipú and Yacyreta binational power plants, in condominium with Brazil and Argentina respectively. Today, Paraguay only consumes a small portion of the energy that corresponds to it, and the surplus is ceded to the condominiums -which compensate Paraguay- according to the regulatory framework established by the Treaties constituting the enterprise.

Notwithstanding other works, they argue that given Paraguay's energy surplus, important advantages could be obtained by encouraging the consumption of its energy through the installation of industries, thus generating jobs and mobilizing the domestic economy, instead of sell their energy, even at a fair price in third-country markets.

Obviously, at least partially, these strategies are mutually exclusive, because the exported energy resigns a potential alternative strategy. Following this line of thought, it is clear that any sale of excess energy will cause the rejection of certain alternatives and consequently 
be linked to an opportunity cost, defined as the maximum value among the options not made. In that sense, it is clear that the strategic use of surplus hydroelectricity that is currently on loan could be key to driving the process of economic and social development of Paraguay;

In this sense, it is very important to support and accompany this process of collective decision-making, with a tool that allows us to consider all options from different perspectives, taking into account the effects that these strategies can have, to materialize, and how they would affect the country's development objectives.

Thus, when comparing the benefits of the different strategies, the impact of these strategies must be considered in different dimensions that affect the socio-economic sectors of the country, i.e. social, economic, environmental dimension, etc.; This makes it necessary not only to define the price levels that make the option to export electric power to the Brazilian electricity market cover the opportunity costs of the other strategies from the economic point of view, but it is also vital to analyze the variations in these costs of opportunity with the consideration of other socio-economic dimensions of interest.

Given this scenario, this paper proposes a methodology to address the problem of decision making raised in Paraguay, based on a model of Process of Analytical Hierarchy (AHP) under five optics or criteria: economic, technical, social, environmental and political, considering as options or alternatives: (A2) the sale of hydroelectric surpluses in the Brazilian wholesale market; (A1) continue with the current situation, transferring the hydroelectric surplus to Brazil (continuing with the normal course of the operation); (A3) install an electro-intensive aluminum industry; and, (A4) a high development of the national industry.

\section{Literature Review}

\subsection{Paraguay's Energy Outlook: Background and Issues}

The country's energy sector presents a paradoxical case. The large hydroelectric power production capacity can be highlighted, as it has three large power plants: Itaipú (ParaguayBrazil), with an installed capacity of 14,000 MW, in equal ownership of energy production for both parties; Yacyretá (Paraguay - Argentina), with an installed capacity of 3,200 MW, of which 1,600 MW belong to Paraguay, and Acaray-exclusive property of the Paraguayan state, with an installed capacity of $210 \mathrm{MW}$.

According to data from the National Energy Balance of 2015, primary energy production is distributed in hydroenergy with $67 \%$ and biomass with $33 \%$. Of this $67 \%$ of hydroenergy produced, about $80 \%$ is sold to the markets of Brazil and Argentina. Electric power participates with only $18.4 \%$ in final energy consumption, with consumption being complemented with petroleum products by $39 \%$ and biomass by $42.6 \%$.

Itaipú Binacional is the main source of electricity in Paraguay, the plant was conceived as a binational treaty signed in 1973 between the governments of Paraguay and Brazil for the development and exploitation of the Paraná River hydroelectric potential. Itaipu produces close to $90,000 \mathrm{GWh} /$ year. Since Paraguay only consumes about $7 \%$ of its total quota, the unused electric power is ceded to Brazil in exchange for an economic compensation established in the 1973 treaty which stipulates that the surplus not consumed by one of the parts, will be transferred to the other contracting party, thus restricting the possibility that one of the parties disposes of its surplus to be sold to third parties. However, as mentioned before, in 2009 opened the possibility of marketing the surpluses of Paraguay directly "only" to the Brazilian free market.

Given this scenario, the main problem lies in the fact that in Paraguay the surplus of available electricity is not used to the maximum, so there is currently a significant share of non-sustainable biomass and oil-based energy sources that represent a clear imbalance in 
the country's energy security, the environment and the quality of life of the population. This situation is not favorable for the country and manifests a clear imbalance that harms the energy security of the country as well as the sustainability of its energy matrix to the detriment of the environment and the quality of life of the population, thus covering all fronts: social, economic and environmental.

\subsection{Opportunity cost}

Analyzing from an economic perspective, we start from the idea that resources are limited and, generally, have different uses. Therefore, there is a need to make decisions taking into account the scarcity of resources. So, for example, the production of a certain good (or the choice of a specific alternative, in the case of decision making) implies the renunciation of manufacturing another product with those same resources (Discard other possible alternatives). The good or service to which those resources have been applied will be expressed in terms of the good or service sacrificed. [11] Making decisions in a world with scarce resources forces us not to choose all the options, which implies the sacrifice of doing something else or another option. This option that is waived or sacrificed is called opportunity cost. [26]

We can speak of three cases in which the opportunity cost takes this value: [27]

- Free goods: These are goods that exist in abundance in nature and whose employment does not generate opportunity costs.

- Factors of a single use: Those resources that can be used in different alternatives have an opportunity cost because when opting for one of them, the rest is being sacrificed. If that resource had only one alternative, its opportunity cost would be zero.

- General unemployment: In general, the elaboration of a good supposes to separate resources from the production of another good. In certain cases, the resources are unemployed and the opportunity cost is zero.

\section{Hypotheses/Objectives}

Determine the opportunity cost of the sale of Paraguayan surplus electricity from Itaipu to the Brazilian electricity market, taking into account multiple criteria.

\section{Analytic Hierarchy Process}

The AHP method was developed during the seventies by Dr. Thomas Saaty, in search of the development of a systematic tool that allows the evaluation and selection of alternatives that have a well-founded framework, solid in its mathematical foundations and simple in its application. The AHP is a systematic tool widely used in the literature for the evaluation and selection of alternatives that have a well-grounded mathematical framework and simple in its application. It allows to derive relative scales using the judgment or standard data, performing later arithmetic operations in such scales. The AHP allows determining relative scales using a weighting or data of a standardized scale, performing the subsequent arithmetic operation in such scales.

\section{Data/Model Analysis:}

A methodology based on an AHP model is proposed to determine the opportunity cost of the sale of Paraguayan energy from Itaipu to the Brazilian market as a decision-making problem in which several possible strategies for utilization of Paraguay's hydro energy surpluses are addressed. Taking into account multiple criteria where the problem based on the AHP model is first structured and then the opportunity costs of the sale of surplus energy from Paraguay to the Brazilian market are determined.

\subsection{Structuring the problem}


Objective: Determine the opportunity cost of the sale of Paraguayan energy from Itaipu to the Brazilian market.

\section{Criteria}

- Environmental Criterion (C1): the indicator of this criterion is the average growth rate of greenhouse gas emissions (GHG), which is estimated by a projection that includes energy consumption as an exogenous variable. The analysis of time series is made based on the historical data of $\mathrm{CO}$ emissions in Paraguay.

- Economic Criterion (C2): the indicator of this criterion is the average annual growth rate of the country's GDP in the horizon analyzed. The GDP projection is estimated through historical time series. Each alternative has special treatment in terms of its marginal contribution to GDP.

- Social Criterion (C3): the indicator of this criterion is the number of jobs that would be generated by each strategy. It is calculated using projections based on historical data or specific additional studies based on the strategy being analyzed.

- Technical Criterion (C4): the indicator of this criterion is the Expected Cost of Energy Not Supplied (CEENS). Within this analysis, the growth rate of electricity demand is considered uncertain and its evolution is replicated through Monte Carlo simulations through a Brownian Movement (BM). In addition, contingency analysis of transmission lines are carried out in each implementation. Finally, Optimal Power Flows (OPF) are calculated in the power system of Paraguay in order to determine the minimum ECENS of each hour, realization and contingency along the analysis horizon.

Feasibility Criteria (C5): here a classification based on expert knowledge of the probability of an effective implementation of the alternatives analyzed is established.

Alternatives:

- A1: Continue transferring electric power to Brazil;

- A2: Sell energy directly to the Brazilian wholesale market. Electricity is sold in the Brazilian wholesale market at different market prices (the prices are established in the following section), generating a net income based on them.

- A3: Encourage the installation of electro-intensive industries: a 1,100 MW aluminum factory is installed in Paraguay in the year 2,017.

- A4: Encourage the National Industry through the development of small industrial parks: Industrial parks of $180 \mathrm{MW}$ per year are established in Paraguay for a period of 4 years. The problem can be represented graphically and can be seen in Fig. 1.

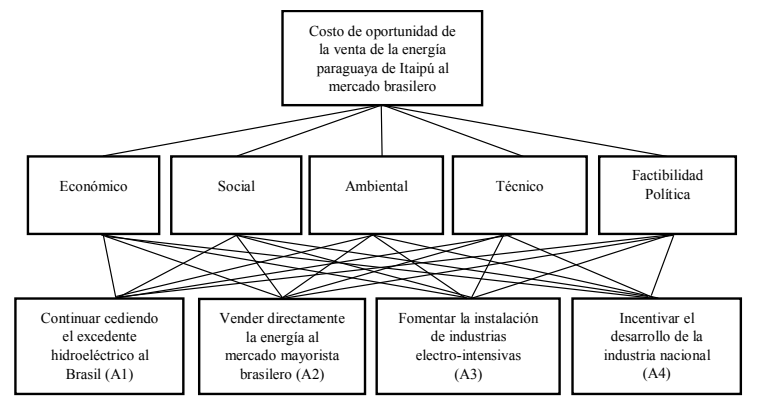

Fig. 1: Hierarchical tree of decisions

\section{Results}

As a result of 145 AHP analyzes, with different prices, it was possible to identify 24 opportunity costs for the "A2" alternative, and the scenarios were determined for which said option clearly represents the best one for the utilization of Paraguay's hydroenergy surpluses. . 
Opportunity costs identified are presented in cases where decision makers have a strong preference for environmental and / or economic criteria. Which is quite logical considering that from the economic point of view, the sale of energy to the Brazilian market is very convenient thanks to the income produced by it. Regarding the environmental aspect, the consumption of energy influences the generation of GHG in Paraguay, so a scenario of high electricity export implies the non-consumption of it, which would reduce the generation of GHG.

Opportunity costs are also presented in scenarios where the social criterion has a marked preference, because as the income from the sale of energy to the Brazilian market increases, an advantage of the income obtained is obtained as a social benefit. Therefore, the opportunity costs identified, and the most convenient, were in combined scenarios of environmental, economic and social criteria preferences.

The general results (The preference of the criteria and sale prices of Paraguayan hydroelectric power) for which an opportunity cost was identified are shown in Fig. 2

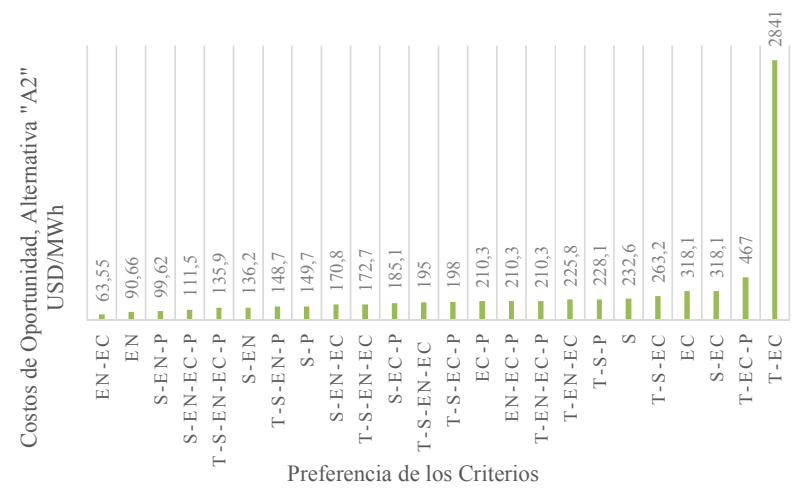

Fig. 2: Opportunity costs identified for alternative A2 taking into account different criteria preferences

\section{Conclusions}

The sale of the surplus electric power of Paraguay in the Brazilian market is a valid option for the use of it, but as can be seen in this study, there are also other possibilities to be considered. It should be noted that the possible alternatives with respect to the use of hydropower surpluses compete with each other, in addition to the fact that there are a number of factors that are not considered in this study; factors that could well influence the decision-making process.

The AHP, the method used for this work, represents a useful scientific tool to analyze in depth the opportunity costs of "Directly selling energy in the Brazilian wholesale market", since in many of the possible scenarios, the aforementioned alternative is not the most convenient.

Another important aspect obtained as a result of this work is the sale prices of energy in the Brazilian market for which revenues would be generated that significantly impact the development of Paraguay, ranging from $63,55 \mathrm{US} \$ \mathrm{MWh}$ to $2481 \mathrm{US} \$ \mathbf{M W h}$. This implies that not all sale prices are really competitive since several of them are very high. It is important, however, to consider all possible lines of action for the management of Paraguay's energy resources.

\section{Key References}

Blanco, G., Amarilla, R., Martinez, A., Llamosas, C., \& Oxilia, V. (2017). Energy transitions and emerging economies: A multi-criteria analysis of policy options for hydropower surplus utilization in Paraguay. Energy Policy, 108, $312-321$.

Saaty, T. L. (2013). Analytic network process. Encyclopedia of operations research and management science, 64-72.

Saaty, T. L., \& Vargas, L. G. (2013). Decision making with the analytic network process: economic, political, social and technological applications with benefits, opportunities, costs and risks (Vol. 195). Springer Science \& Business Media. 